\title{
Digestibility, rumen protozoa, and ruminal fermentation in goats receiving dietary palm oil by-products
}

\begin{abstract}
Sixteen goats fitted with a rumen cannula were used in completely randomized block design to test the effects of dietary crude palm oil (PO), palm kernel cake (PKC) and decanter cake (DC) on rumen total protozoa counts, rumen fermentation, and digestibility. Goats received once daily (1.5\% of BW) one of four concentrate diets: reference diet (RD), DC diet (DCD), PKC diet (PKCD) and RD plus 5\% PO diet (CPOD). The RD was based on corn grain and soybean meal and was fed to all goats for 28 days before the start of a 30-day experiment. Organic matter $(\mathrm{OM})$ digestibility was reduced $(\mathrm{P}<0.05)$ by feeding $\mathrm{DCD}$, whereas digestibility of acid detergent fiber $(\mathrm{ADF})$ was higher $(\mathrm{P}<0.0001)$ in the goats fed PKCD. The digestibility of neutral detergent fiber $(\mathrm{NDF})$ was higher $(\mathrm{P}<0001)$ in goats fed $\mathrm{PKCD}$ followed by those fed DCD, CPOD and CD. Ammoniaï N concentration was lower $(\mathrm{P}<$ 0.001) for treatments DCD, PKCD and CPOD than for treatment RD. Volatile fatty acid (VFA) concentrations were lower $(\mathrm{P}<0.05)$ for treatments PKCD and CPOD than for treatments RD and DCD. Total protozoa counts were higher $(\mathrm{P}<0.001)$ for treatment $\mathrm{CD}$ than for other treatments. It was concluded that the dietary DC, and PKC could be included in the diet of goats up to $80 \%$ without any adverse effects on dry matter intake; however, rumen fermentation parameters and total protozoa counts were changed.
\end{abstract}

Keyword: Decanter cake; Digestibility; Goat; Palm kernel cake; Palm oil; Rumen protozoa 